\title{
Improving Software Development Process Implemented in Team Project Course
}

\author{
Iwona Dubielewicz and Bogumiła Hnatkowska \\ Institute of Applied Informatics, Wroclaw University of Technology, \\ Wyb. Wyspianskiego 27, 50-370 Wroclaw, Poland \\ \{Iwona.Dubielewicz, Bogumila.Hnatkowska\}@pwr.wroc.pl
}

\begin{abstract}
The paper presents an assessment approach to software development process used within students' team project. The assessment is based on exemplary Process Assessment Model given in ISO/IEC 15504-5 standard. The results of the assessment suggest the area of improvement in our software development process realization. The history, context and basic assumptions established and proposed for the future improvements in the course are given.
\end{abstract}

Keywords: team project, software development, process assessment model.

\section{Introduction}

Software engineering (SE) is a discipline of developing and maintaining software systems that behave reliably and efficiently, are prepared for future enhancement and modification, and satisfy the requirements that customers have formulated for them. Students of SE during their program of study should participate in the development of software of real-world software.

To fulfill the industrial postulate of incorporating professional practice into the curriculum, since 1998 we have been offering a Software Development Course (SSD). During this course students work in teams on design and implementation of projects that involve consideration of real-word issues including safety, efficiency, and suitablity for the intended users.

Usually every educational course after several editions is a subject to change. It is especially true for software area because of the rapid changes in the field of software engineering. Similarly to software development, the course development can be divided into four phases: specification, design, implementation, and assessment. Even though a course specification is stable and is performed only once, design and implementation of the course is not a one-time process but rather a "work in progress" i.e. it can be seen as an iterative process. In order to conduct the next course iteration one should know the results from the assessment of the previous one.

The main aim of the paper is:

- $\quad$ to present an assessment carried out for the existing software development process implemented in project course; the assessment process is based on the assessment model as it is proposed in ISO/IEC 15504-5 [3] standard, 
- $\quad$ to figure out the elements which could be changed in order to reach the higher quality of this process, and

- $\quad$ to propose a technical tool aiding of new quality-oriented activities.

We expect that due to more formal process assessment of course implementation we will get a strong rationale for the course modification.

The paper consists of four sections. Section 2 presents briefly a model of process assessment as defined in [2], [3]. Section 3 describes an assessment of the taught process and gives some suggestions how it could be change for better quality. Section 4 summarizes the paper.

\section{Model of Process Assessment}

An assessment of software development process can be conducted according to ISO 15504-2 standard [2]. Process Assessment Model (PAM) is used as a common basis for performing assessments of software engineering process capability. PAM is a twodimensional model of process capability. The considered dimensions are:

1. the process dimension, where processes are defined and classified into process categories; further these categories are decomposed into groups.

2. the capability dimension, where a set of process attributes grouped into capability levels is defined; these process attributes provide the measurable characteristics of process capability.

In the process dimension there are distinguished three categories of processes: primary, supporting and organizational. An individual process is described in terms of process name, purpose, and outcomes [1]. For example in Table 1 Software construction process is described.

In PAM every process is extended with additional information in the form of:

- a set of base practices for the process providing a definition of the tasks and activities needed to accomplish the process purpose and fulfil the process outcomes; each base practice is explicitly associated to a process outcome (see Table 1 the line named Base Practices);

- a list of input and output work products associated with each process and related to one or more of its outcomes; each work product has some characteristics associated.

PAM is based on the principle that the capability of a process can be assessed by demonstrating the achievement of process attributes on the basis of evidences related to assessment indicators. There are two types of assessment indicators: process capability indicators, that can be applied to capability levels 1 to 5 , and process performance indicators, that can be applied exclusively to capability level 1 .

Process capability indicators are as follows:

- $\quad$ Generic Practice (GP);

- Generic Resource (GR);

- Generic Work Product (GWP). 
These indicators concern significant activities, resources and or results associated with the process. The existence of these indicators provides evidence of process capability.

Table 1. Exemplary process description in PAM (the source: [3])

\begin{tabular}{ll}
\hline Process & ENG.6 \\
ID & \\
\hline Name & Software construction \\
Purpose & $\begin{array}{l}\text { The purpose of the Software construction process is to produce executable } \\
\text { software units that properly reflect the software design. }\end{array}$ \\
Outcomes & $\begin{array}{l}\text { As a result of successful implementation of Software construction process: } \\
\text { 1) verification criteria are defined for all software units against their require- } \\
\text { ments; }\end{array}$ \\
& 2) software units defined by the design are produced; \\
& 3) consistency and traceability are established between software requirements \\
and design and software units; and
\end{tabular}

In Table 2 the examples of mapping from the defined generic practices (GP x.y.z) to the relevant process attributes (PA.X.y.z) are given.

A capability level is a set of process attribute(s) that provide a major enhancement in the capability to perform a process. There are defined six process capability levels: 0-incomplete, 1-performed, 2-managed, 3-established, 4-predicable, 5-optimizing. Every capability level attribute is described in structured, standardized form [3]. An example of such a description for the attribute of process performance indicator of the $1^{\text {st }}$ level is presented below:

\section{Level 1: Performed process}

\section{PA 1.1 Process performance attribute}

The process performance attribute is a measure of the extent to which the process purpose is achieved. As a result of full achievement of this attribute:

a) the process achieves its defined outcomes.

Generic Practices for PA 1.1:

- $\quad$ Achieve the process outcomes;

- Perform the intent of the base practices;

- Produce work products that evidence the process outcomes;

Generic Resources for PA 1.1:

- Resources are used to perform the intent of process specific base practices [PA 1.1 Achievement a] 
Table 2. Exemplary relationships between generic practices and process attributes ([3])

\begin{tabular}{|c|c|c|}
\hline GP & Practice Name & Maps to \\
\hline \multicolumn{3}{|c|}{ PA 1.1: Process performance attribute } \\
\hline GP 1.1.1 & Achieve the process outcomes. & PA.1.1.a \\
\hline \multicolumn{3}{|c|}{ PA 2.1: Performance management attribute } \\
\hline GP 2.1.1 & Identify the objectives for the performance of the process. & PA.2.1.a \\
\hline GP 2.1.2 & $\begin{array}{l}\text { Plan and monitor the performance of the process to fulfill the } \\
\text { identified objectives. }\end{array}$ & PA.2.1.b \\
\hline GP 2.1.3 & Control the performance of the process. & PA.2.1.c \\
\hline GP 2.1.4 & Define responsibilities and authorities for performing the process. & PA.2.1.d \\
\hline GP 2.1.5 & $\begin{array}{l}\text { Identify and make available resources to perform the process } \\
\text { according to plan. }\end{array}$ & PA.2.1.e \\
\hline GP 2.1.6 & Manage the interfaces between involved parties. & PA.2.1.f \\
\hline \multicolumn{3}{|c|}{ PA 2.2: Work product management attribute } \\
\hline GP 2.2.1 & Define the requirements for the work products. & PA.2.2.a \\
\hline GP 2.2.2 & Define requirements for documentation and control of work products. & PA.2.2.b \\
\hline GP 2.2.3 & Identify, document and control the work products. & PA.2.2.c \\
\hline GP 2.2 .4 & Review and adjust work products to meet the defined requirements. & PA.2.2.d \\
\hline
\end{tabular}

\section{Generic Work Products for PA 1.1}

- Work products exist that provide evidence of the achievement of the process outcomes [PA 1.1 Achievement a]

All process attributes for all capability levels are given in Table 3 . In this table it is also defined what attribute ratings are required for a process to be categorized as being on the appropriate level of capability.

Table 3. Process Capability levels and their attributes

\begin{tabular}{lll}
\hline Capability level & Process attribute & Attribute rating \\
\hline Level 0: Incomplete & Incomplete & $\mathrm{N} / \mathrm{P}$ \\
Level 1: Performed & Process Performance & $\mathrm{L} / \mathrm{F}$ \\
Level 2: Managed & Level 1+ & $\mathrm{F}$ \\
& Performance Management, Work prod. Management & $\mathrm{L} / \mathrm{F}$ \\
Level 3: & Level 2+ & $\mathrm{F}$ \\
Established & Process Definition, Process Deployment & $\mathrm{L} / \mathrm{F}$ \\
Level 4: Predictable & Level 3+ & $\mathrm{F}$ \\
& Process Measurement, Process Control & L/F \\
Level 5: & Level 4+ & $\mathrm{F}$ \\
Optimizing & Process Innovation, Continuous Optimization & L/F \\
\hline
\end{tabular}

where symbols of attribute rating are interpreted as follows:

$\begin{array}{lll}N & \text { Not achieved } & \text { i.e. } 0 \text { up to } 15 \% \text { attribute achievement } \\ P & \text { Partly achieved } & \text { i.e. }>15 \% \text { up to } 50 \% \text { attribute achievement } \\ L & \text { Largely achieved } & \text { i.e. }>50 \% \text { up to } 85 \% \text { attribute achievement } \\ F & \text { Fully achieved } & \text { i.e. }>85 \% \text { up to } 100 \% \text { attribute achievement }\end{array}$




\section{Improvement of Software Development Process Implemented in SSD Course}

\subsection{Historical Background}

The considered software development process is implemented within team project classes offered since 1999. Initially students followed USDP [6] methodology, but since 2004 we have introduced RUP process [7]. The previous editions of SSD course are described in [4], and [5].

As this project corresponds to the concept of the capstone course, it has three common elements of capstone programs:

1) students are divided into teams of typically 4 to 6 students each; one of them plays a role of the project manager and the lecturer plays a supervisor/auditor role;

2) each team is given a real-world project or problem to solve;

3) this project takes 30 weeks to complete (it is continued along two semesters 60 class-hours, offered within $7^{\text {th }}$ and $8^{\text {th }}$ semesters for about 120 students every year).

The project constitutes a part of a subject called System Software Development.

Before attending the course we require the students have finished the courses of object-oriented programming, UML [8], fundamentals of databases. In parallel the students are offered software project management and database design courses.

Design and implementation of software system belongs to the important activities within project. We suggest students to use multi-tiers architecture as well as component techniques. The target system architecture should be distributed between at least two tiers. Client-server is the most often selected system architecture.

\subsection{Assessment of Current Software System Development Process}

The students are obliged to use customized RUP approach while developing software system within SSD project. Comparing attributes of our implemented development process to these given in [3], we can recognize that our process is at least on the $1^{\text {st }}$ capability level.

According to [2] the process is performed when it fully achieves its performance attribute due to achieving its defined outcomes. In Table 4 there are presented selected implemented workflows (GP), required work products (GWP) and some of resources used in process (GR).

To establish how far is our process from the $2^{\text {nd }}$ level of capability we have to point out that our performed process is implemented in a managed fashion (planned, monitored and adjusted) and its work products are appropriately established, controlled and maintained (see Table 3).

We have decided to performed such assessment for limited numbers of attributes, which, in our opinion need to be improved. The same approach to assessment might be conducted for all attributes defined in [3] for managed process. 
Table 4. Software system development work products

\begin{tabular}{|c|c|c|c|}
\hline RUP discipline & Work products & Notes & Tools \\
\hline Requirements & $\begin{array}{l}\text { Vision, Glossary } \\
\text { Supplementary Specifica- } \\
\text { tion } \\
\text { Use Case Model } \\
\text { Use-Case specifications } \\
\text { User-interface prototype }\end{array}$ & $\begin{array}{l}\text { Sketches of GUI-interface, } \\
\text { screen shots or executable GUI } \\
\text { prototype. }\end{array}$ & $\begin{array}{l}\text { Requisite Pro } \\
\text { Rational Rose }\end{array}$ \\
\hline Design & $\begin{array}{l}\text { Design Model } \\
\text { Deployment Model } \\
\text { Data Model, SAD } \\
\text { Deployment Model }\end{array}$ & & $\begin{array}{l}\text { Rational Rose } \\
\text { SoDa }\end{array}$ \\
\hline Test & $\begin{array}{l}\text { Test plan, Defects list } \\
\text { Test evaluation summary } \\
\text { Defects list }\end{array}$ & & $\begin{array}{l}\text { Test Factory } \\
\text { (option) } \\
\text { Clear Quest }\end{array}$ \\
\hline $\begin{array}{l}\text { Project man- } \\
\text { agement }\end{array}$ & $\begin{array}{l}\text { Iteration Plan } \\
\text { (from } 2^{\text {nd }} \text { iteration) } \\
\text { Iteration Assessment } \\
\text { Use-case priorities }\end{array}$ & $\begin{array}{l}\text { Software Development Plan was } \\
\text { elaborated by a teacher. } \\
\text { Risk list is limited to use-case } \\
\text { priorities. }\end{array}$ & \\
\hline Environment & $\begin{array}{l}\text { Project specific guidelines } \\
\text { (option) }\end{array}$ & $\begin{array}{l}\text { Design guidelines } \\
\text { Programming guidelines. }\end{array}$ & \\
\hline
\end{tabular}

Table 5 gathers information about performance management attributes for assessment - they are described by letters from A to D. Particular indicators are evaluated subjectively - in 0-5 point scale - basing on our expectations and experiences. Some comments about each element rate are put below. The process in considered area is partially achieved (42\%).

Ad. A) Better monitoring of the project progress and tasks realization is needed. Now each team prepares weekly reports for team supervisor. The control over the project from the supervisor's perspective is relatively small. Tasks to be performed within a concrete iteration should be communicated in a readable way.

Ad. B) More flexible treatment of iteration content is needed. The disciplines performed within the project should be carefully selected, e.g. in many cases full business modeling is spared.

Ad. C) Easier access to templates and examples of artifacts used during software development is needed. The artifacts should be clearly described; now they are distributed as packed zip archives.

Ad. D) Improved communication inside the development team as well as between the development team and the supervisor is needed; now, the direct contact between the supervisor and a team is usually limited to $30 \mathrm{~min}$ a week; it is often too short, so additional information is exchanged by e-mails or printed documents; the feedback is rather low and late.

Table 6 gathers information about attributes needed for assessment of work product management attributes (row E). Some comments about each element rate are put below the table. The process in considered area is partially achieved (30\%). 
Table 5. Assessment of performance management attributes

\begin{tabular}{|c|c|c|c|c|}
\hline ID & Attribute & $\begin{array}{l}\text { Indi- } \\
\text { cator }\end{array}$ & Element to be assessed & $\begin{array}{l}\text { Assessment } \\
{[0-5] \text { scale }}\end{array}$ \\
\hline \multirow[t]{3}{*}{ A } & \multirow{3}{*}{$\begin{array}{l}\text { Performance of } \\
\text { the process is } \\
\text { planned and } \\
\text { monitored }\end{array}$} & GP & $\begin{array}{l}\text { a.1) Process performance is monitored to } \\
\text { ensure that planned results are achieved }\end{array}$ & $\begin{array}{l}2 \text { (rarely, man- } \\
\text { ual) }\end{array}$ \\
\hline & & GR & a.2) Workflow management system & 0 (none) \\
\hline & & GWP & $\begin{array}{l}\text { a.3) Contains status information about } \\
\text { corrective actions; schedule and work }\end{array}$ & $\begin{array}{l}2 \text { (incomplete, } \\
\text { not up to date) }\end{array}$ \\
\hline \multirow[t]{4}{*}{ B } & \multirow{4}{*}{$\begin{array}{l}\text { Performance of } \\
\text { the process is } \\
\text { adjusted to meet } \\
\text { plans }\end{array}$} & GP & b.1) The plan(s) are adjusted, as necessary, & 3 (very rarely) \\
\hline & & & b.2) Rescheduling is done when necessary. & 2 (very rarely) \\
\hline & & GR & $\begin{array}{l}\text { b.3) Facilities and infrastructure resources } \\
\text { are available }\end{array}$ & 0 (fully manual) \\
\hline & & GWP & $\begin{array}{l}\text { b.4) Process definition describes the way } \\
\text { of plan controlling and adjusting }\end{array}$ & $\begin{array}{l}2 \text { (not formal- } \\
\text { ised) }\end{array}$ \\
\hline \multirow[t]{3}{*}{$\mathrm{C}$} & \multirow{3}{*}{$\begin{array}{l}\text { Resources and } \\
\text { information } \\
\text { necessary for } \\
\text { performing the } \\
\text { process are } \\
\text { identified, made } \\
\text { available, allo- } \\
\text { cated and used }\end{array}$} & GP & $\begin{array}{l}\text { c.1) The human and infrastructure resour- } \\
\text { ces necessary to performed the process are } \\
\text { defined, made available, allocated and } \\
\text { used. }\end{array}$ & $\begin{array}{l}4 \text { (distributed as } \\
\text { zip files) }\end{array}$ \\
\hline & & GR & $\begin{array}{l}\text { c.2) Information and/or experiences reposi- } \\
\text { tory. }\end{array}$ & 3 (zip files) \\
\hline & & GWP & $\begin{array}{l}\text { c.3) States results achieved or provides } \\
\text { evidence of activities performed in a proc- } \\
\text { ess. }\end{array}$ & $\begin{array}{l}2 \text { (not up to } \\
\text { date) }\end{array}$ \\
\hline \multirow[t]{3}{*}{$\mathrm{D}$} & \multirow{3}{*}{$\begin{array}{l}\text { Interfaces be- } \\
\text { tween involved } \\
\text { parties are man- } \\
\text { aged }(\ldots)\end{array}$} & GP & $\begin{array}{l}\text { d.1) Communication between the involved } \\
\text { parties is effective }\end{array}$ & \multirow[t]{3}{*}{$\begin{array}{l}3 \text { (weekly meet- } \\
\text { ings) }\end{array}$} \\
\hline & & GR & None & \\
\hline & & GWP & None & \\
\hline \multicolumn{2}{|c|}{ Summary } & & & $(42 \%)$ \\
\hline
\end{tabular}

Table 6. Assessment of work product management attributes

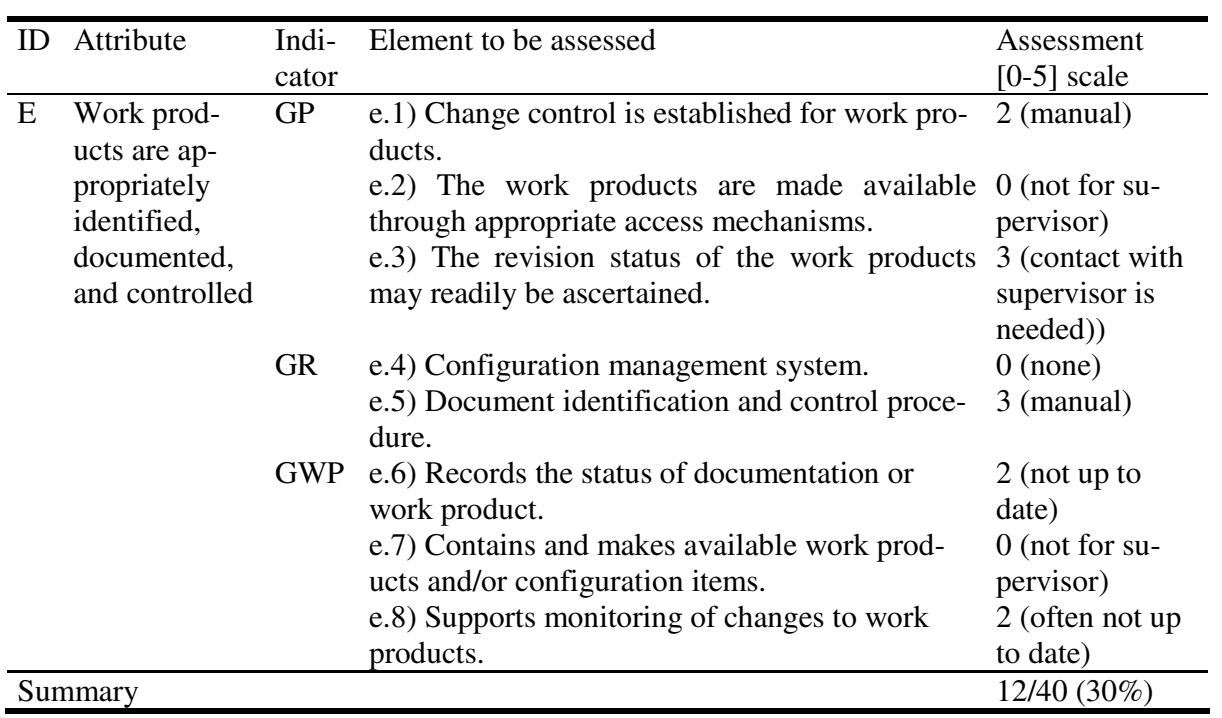


Ad. E) There is a need for introducing commonly used change and version control mechanisms for artifacts (especially documents). Now, a team is responsible for assuring both mechanisms. The supervisor has limited access and thus not complete knowledge on about the document versions, their authors, and the reasons of changes.

\subsection{Proposed Solution}

This section presents how the generic elements, identified and described in section 3.1 , are to be instantiated within software system developing process. The solution will be implemented during following semester. The main element of the solution is Office SharePoint Server 2007 [9] that is used within the Institute of Applied Informatics as a LMS e-learning platform and as a portal for document management.

SharePoint supports business life cycle of design documents. All documents prepared by a particular team are stored and versioned by SharePoint server. Creation of new documents is simplified due to possibility of using templates.

In SharePoint a document can be in one of four states: draft, pending, approved, rejected. The document is in draft state after creation. Within this state document can be modified and updated many times. History of document revisions is available for both the team and the supervisor. The team can change the state of document to pending see fig. 1. That means, that the document is ready to be checked. If the document verification is successful the supervisor changes its state to approved, otherwise - to rejected state. The team is obligated to prepare a new version of rejected document the life cycle of such document begins once again. The information about the authors/updaters of each document could be easily obtained (realization of c.3, d.1, e.3e. 8 - tables 5 and 6).

\begin{tabular}{|c|c|c|}
\hline Stownik biznesowy & Student First & Approved \\
\hline Słownik systemowy & Student Two & Draft \\
\hline Zgloszenie tematu & Student First & Pending \\
\hline
\end{tabular}

Fig. 1. Information about work product state

SharePoint supports monitoring of design tasks and design progress. Iteration plan for $1^{\text {st }}$ iteration is prepared by team supervisor. Plans of subsequent iterations are prepared by team managers. The plan is visualized by Gantt's graph - see fig. 2 (realization of a.1, a.2, a.3).

Any plan rescheduling has to be agreed with the supervisor. After that a team manager is allowed to introduce changes into iteration breakdown (realization of b.1, b.2, b.3). Each week the supervisor controls project progress according to the plan. Usually the supervisor asks for reasons of noticed delays and, if they are important he/she talks over the possible corrective actions and/or about the rearrangement of schedule (realization of b.4).

Discussion forum and wiki pages enable knowledge transfer between all stakeholders within the process, i.e. students, domain experts, IT experts etc. (realization of c.2). Table 7 presents assessment of a current process (CSA) and a priori assessment of proposed solution (FSA). We hope the process will move to fully achieved 2nd capability level in the considered area. 


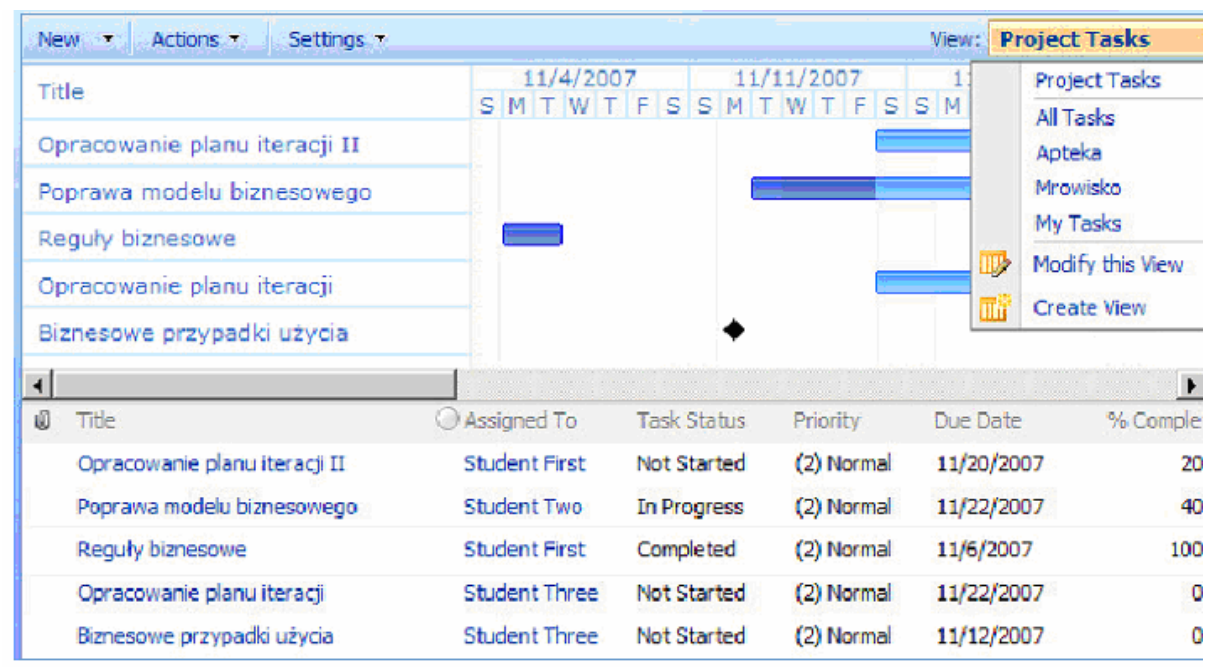

Fig. 2. Iteration process breakdown

Table 7. A priori assessment of planned improvements

\begin{tabular}{lclccc}
\hline Element & $\begin{array}{c}\text { CSA } \\
{[\mathbf{0 - 5}]}\end{array}$ & $\begin{array}{c}\text { FSA } \\
{[\mathbf{0 - 5}]}\end{array}$ & $\begin{array}{c}\text { Element } \\
\text { CSA } \\
{[\mathbf{0 - 5}]}\end{array}$ & $\begin{array}{c}\text { FSA } \\
{[\mathbf{0 - 5}]}\end{array}$ \\
\hline a.1) & 2 & 4 (planned and documented) & $\mathrm{e} .1)$ & 2 & 5 \\
a.2) & 0 & 5 & $\mathrm{e} .2)$ & 0 & 5 \\
a.3) & 2 & 4 (omits corrective actions) & $\mathrm{e} .3)$ & 3 & 5 \\
b.1) & 3 & 5 & $\mathrm{e} .4)$ & 0 & 5 \\
b. 2$)$ & 2 & 5 & $\mathrm{e} .5)$ & 3 & 5 \\
b.3) & 0 & 5 & $\mathrm{e} .6)$ & 2 & 5 \\
b.4) & 2 & 5 & $\mathrm{e} .7)$ & 0 & 5 \\
c.1) & 4 & 5 & $\mathrm{e} .8)$ & 2 & 5 \\
c. 2$)$ & 3 & 4 (acceptance procedure is needed) & & & \\
c.3) & 2 & 5 & & & \\
d.1) & 3 & 4 (communication not guaranteed) & & Summary & $40 / 40100 \%$ \\
\hline \multicolumn{7}{c}{ Summary } & $49 / 5589 \%$ &
\end{tabular}

\section{Summary}

The aim of the paper was to show how to evaluate a process capability level and point out these task and activities in a process implementation improving of which would rise up a capability level. The assumption is that the process should be capable in terms of ISO/IEC 15504-2 assessment model.

Up to now the software development process was at least at $1^{\text {st }}$ performed capability level. It results from the fact that it is a customised version of RUP methodology. The RUP disciplines: Configuration, and Change Management and Project Management need improvement in our opinion. The elements of these two disciplines were assessed to fulfil requirements defined for the managed level (according to Process 
Assessment Model described in [3]). The solution aiming at improvement of the software development process in considered area and moving the process from partially achieved to fully achieved attributes was also described.

The key element of the solution is based on application of Office SharePoint 2007 Server. The solution is fully developed by the students attending the course. It is planned for deployment during the following semester. Its a posteriori assessment will be possible in six months.

\section{References}

1. ISO/IEC 12207:1995/Amd.1:2002; Amd.2:2004, Information technology - Software life cycle processes (2004)

2. ISO/IEC 15504-2:2003, Information technology - Process assessment - Part 2: Performing an assessment (2003)

3. ISO/IEC 15504-5:2006, Information technology - Process assessment - Part 5: An exemplar Process Assessment Model (2006)

4. Dubielewicz, I., Hnatkowska, B.: Teaching of Information system modeling with UML. In: Proceeding of International Conference MOSIS 2000, Roznov, Czech Republic 2000, pp. 149-159 (2000)

5. Dubielewicz, I., Hnatkowska, B.: RUP customization in teaching of system software development. In: Benes, M. (ed.) Proceedings of the 7th ISIM conference. Acta MOSIS, MARQ 2004, Ostrava, vol. 96, pp. 19-27 (2004)

6. Jacobson, I., Booch, G., Rumbaugh, J.: The Unified Software Development Process. Addison-Wesley, Reading (1999)

7. Rational Unified Process, Rational Software Corporation (2003)

8. OMG Unified Modeling Language Specification, Version 1.4 (2001)

9. Microsoft Office SharePoint Server (2007), http://office.microsoft.com/ pl-pl/sharepointserver/FX100492001045.aspx 